University of Nebraska - Lincoln

DigitalCommons@University of Nebraska - Lincoln

Papers in the Earth and Atmospheric Sciences Earth and Atmospheric Sciences, Department

7-15-1994

\title{
Springtime Microwave Emissivity Changes in the Southern Kara
}

Sea

Robert G. Crane

Pennsylvania State University, rqc3@psu.edu

Mark R. Anderson

University of Nebraska-Lincoln, manderson4@unl.edu

Follow this and additional works at: https://digitalcommons.unl.edu/geosciencefacpub

Part of the Earth Sciences Commons

Crane, Robert G. and Anderson, Mark R., "Springtime Microwave Emissivity Changes in the Southern Kara Sea" (1994). Papers in the Earth and Atmospheric Sciences. 180.

https://digitalcommons.unl.edu/geosciencefacpub/180

This Article is brought to you for free and open access by the Earth and Atmospheric Sciences, Department of at DigitalCommons@University of Nebraska - Lincoln. It has been accepted for inclusion in Papers in the Earth and Atmospheric Sciences by an authorized administrator of DigitalCommons@University of Nebraska - Lincoln. 


\title{
Springtime microwave emissivity changes in the southern Kara Sea
}

\author{
Robert G. Crane \\ Earth System Science Center and Department of Geography, The Pennsylvania State University, University \\ Park
}

\author{
Mark R. Anderson \\ Department of Geography, University of Nebraska, Lincoln
}

\begin{abstract}
Springtime microwave brightness temperatures over first-year ice are examined for the southern Kara Sea. Snow emissivity changes are revealed by episodic drops in the 37- to 18-GHz brightness temperature gradient ratio measured by the Nimbus 7 scanning multichannel microwave radiometer. We suggest that the negative gradient ratios in spring 1982 result from increased scatter at $37 \mathrm{GHz}$ due to the formation of a near-surface hoar layer. This interpretation is supported by the results of a surface radiation balance model that shows the melt signature occurring at below freezing temperatures but under clear-sky conditions with increased solar input to the surface. Published observations from the Greenland ice cap show a surface hoar layer forming under similar atmospheric conditions owing to the increased penetration and absorption of solar radiation just below the surface layer. In spring/early summer 1984 similar gradient ratio signatures occur. They appear to be due to several days of freezethaw cycling following the movement of a low-pressure system through the region. These changes in surface emissivity represent the transition from winter to summer conditions (as defined by the microwave response) and are shown to be regional in extent and to vary with the synoptic circulation.
\end{abstract}

\section{Introduction}

The energy budget over sea ice is largely determined by the radiation balance at the surface. This balance changes rapidly during the melt season, when the physical properties of the surface are altered; the most dramatic effects are shown in the surface albedo during the progression from snow melt to ice breakup. The albedo for sea ice with a fresh snow cover is about $75-80 \%$. This decreases to about $40-60 \%$ for old ice and drops to about $10 \%$ for open water. As melt progresses, there is a significant decrease in the regional albedo [Robinson et al., 1986, 1992]. The springtime transition from winter to summer conditions thus represents a critical period when ocean-atmosphere interactions undergo rapid fluctuations owing to changing snow cover conditions, ice thickness, and ice concentration.

This transition period takes on added significance when one considers the results of several modeling experiments that suggest that the equilibrium ice thickness is strongly influenced by the surface albedo parameterization and the timing of the snow melt [Shine and Crane, 1984; Shine and Henderson-Sellers, 1985; Ledley, 1991]. Similarly, all of the current general circulation model experiments for a doubled $\mathrm{CO}_{2}$ climate show a considerable enhancement of the warming at

Copyright 1994 by the American Geophysical Union.

Paper number $94 \mathrm{JC} 00381$.

0148-0227/94/94JC00381 \$05.00 high latitudes, with much of the warming being attributed to the temperature-albedo feedback in the seasonal sea ice zone (SSIZ), the region of high-latitude seas that experiences a seasonal ice cover [e.g., Dickinson et al., 1987]. Consequently, it becomes even more important that we develop a clearer understanding of ice processes during this period in the seasonal cycle to validate the results of both atmospheric and oceanic circulation models and of stand-alone dynamic and thermodynamic models of the polar sea ice cover.

Several hypotheses concerning spring melt could be suggested, the simplest and most obvious being that melt will follow a zonal progression related to the latitudinal change in the solar forcing with time throughout the melt season. An alternative possibility is that the melt would vary on a local basis according to regional features of the synoptic-scale atmospheric circulation. Tentative support for this second hypothesis comes from earlier work by Crane et al. [1982] using data from the single channel electrically scanning microwave radiometer on Nimbus 5. The synoptic pattern of snow melt over the sea ice is further demonstrated in the present paper; we suggest that spring and early summer changes in satellitederived microwave brightness temperatures occur on a regional basis in response to the surface radiation budget and synoptic variations in cloud cover. From the perspective of passive microwave radiometry, these emissivity changes represent the start of the transition from winter to summer ice conditions.

Crane and Anderson [1989] describe the spring melt pattern in the Kara/Barents Sea in 1984, suggesting that changes in the ice cover in the Barents Sea were dominated by ice advection, while ice conditions in the Kara Sea were domi- 
nated by surface melt processes. The present paper concentrates on the Kara Sea but focuses on microwave emissivity changes occurring in the spring and early summer. In previous work we have suggested that similar changes observed in other parts of the SSIZ might be attributed to an increase in grain size within the snow pack [Anderson, 1987; Crane and Anderson, 1989]. Earlier work by Anderson and Robinson [1985] also shows that the areas where this signal appears are the same regions in which snow melt first becomes apparent in the visible-band satellite imagery, but the change is observed in the microwave brightness temperatures several weeks before it can be seen in the visible-band data.

\section{Spring/summer microwave signatures of snow covered sea ice}

The sea ice data are vertically polarized brightness temperatures from the $18-\mathrm{GHz}$ and $37-\mathrm{GHz}$ channels of the Nimbus 7 scanning multichannel microwave radiometer (SMMR). The SMMR is a dual polarized five-frequency instrument with channels at 6.6, 10.69, 18.0,21.0, and $37.0 \mathrm{GHz}$. The resolution is frequency dependent and varies from $148 \mathrm{~km}$ by 151 $\mathrm{km}$ at $6.6 \mathrm{GHz}$ to $27 \mathrm{~km}$ by $32 \mathrm{~km}$ at $37 \mathrm{GHz}$. The present study uses the daily averaged $18-\mathrm{GHz}$ and $37-\mathrm{GHz}$ channels mapped to the $25-\mathrm{km}$ special sensor microwave/imager grid available on CD-ROM. The sensor operated only on alternate days owing to power limitations. The data presented in Figures 1 and 2 thus represent observations made at 2-day intervals.

For microwave remote-sensing purposes, the ice cover is usually assumed to be a simple mix of first-year ice, multiyear ice, and open water. Multiyear ice in a microwave context is ice that has undergone the transition to a lower-density, less saline ice pack following brine drainage during the summer melt season. Differences in emissivity between ice and open water and the variation in emissivity with frequency for firstyear and multiyear ice are used for the operational retrieval of ice type and concentration [Cavalieri et al., 1984; Gloersen and Cavalieri, 1986]. The method is based on empirically derived functions that utilize two spectral ratios. The first is a polarization ratio with the polarization difference between ice

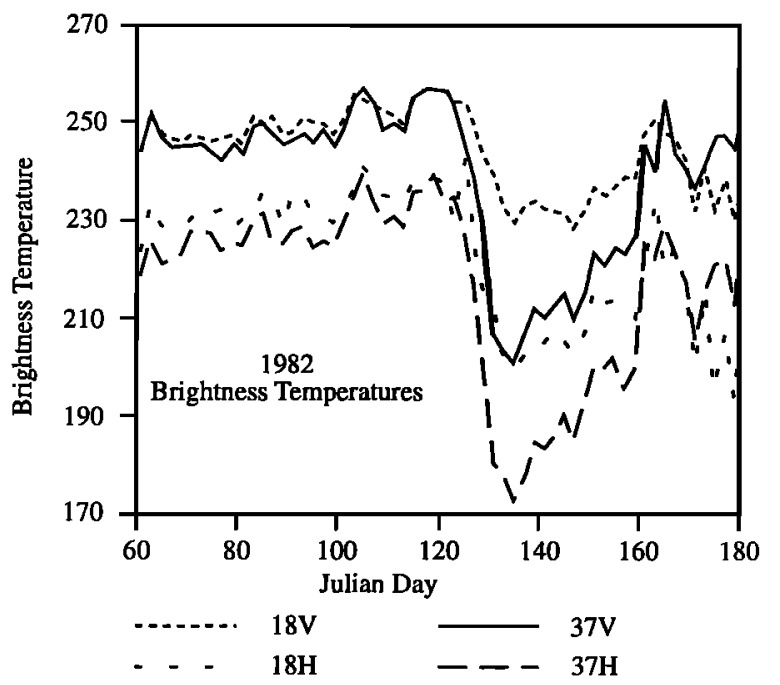

and open water being used to estimate ice coverage. The second uses a spectral gradient ratio to derive information on ice type (the multiyear ice fraction). The gradient ratio makes use of the emissivity difference between first-year and multiyear ice, which changes as a function of frequency, with the difference between the 37-GHz and 18-GHz emissivities being positive for first-year ice and strongly negative for multiyear ice. Snow cover is usually neglected in these calculations.

The limited snow cover observations that are available suggest that snow depth generally varies from about 0 to 1.0 $\mathrm{m}$ with a mean of about 0.2-0.4 m [Hanson, 1980; Barry, 1983]. Since the skin depth for dry snow (in the SMMR frequency range) is of the order of 0.5 to $2.0 \mathrm{~m}$, it is usually assumed that except for an unusually thick snow cover or during the melt season, snow will have little effect on the brightness temperature over sea ice [Zwally and Gloersen, 1977; Chang et al., 1976, 1982]. During melt, however, several changes occur that do influence the emissivity. The most dramatic of these is a substantial increase in emissivity when the pack becomes "wet." As the pack warms to the melting point, there is an increase in the free-water content of the pack, which forms a thin film around the grains. This film reduces internal scatter and increases the emissivity for all ice types at all frequencies [Stiles and Ulaby, 1980; Livingstone et al., 1987]. The resulting spike in microwave brightness temperatures is usually assumed to mark the transition to summertime ice conditions, during which time the effectiveness of the operational ice retrieval algorithms are considerably reduced. The present paper demonstrates that equally significant snow emissivity changes may occur earlier in the spring, before substantial warming has occurred, and that these changes may also have a large impact on ice retrievals.

Because of their frequency dependence, the snow emissivity effects are also observed in the gradient ratio referred to above. In this case the spectral gradient ratio uses the difference between the $18-\mathrm{GHz}$ and $37-\mathrm{GHz}$ vertically polarized brightness temperatures and is given by

$$
G R=\frac{T B_{v, 37}-T B_{v, 18}}{T B_{v, 37}+T B_{v, 18}}
$$

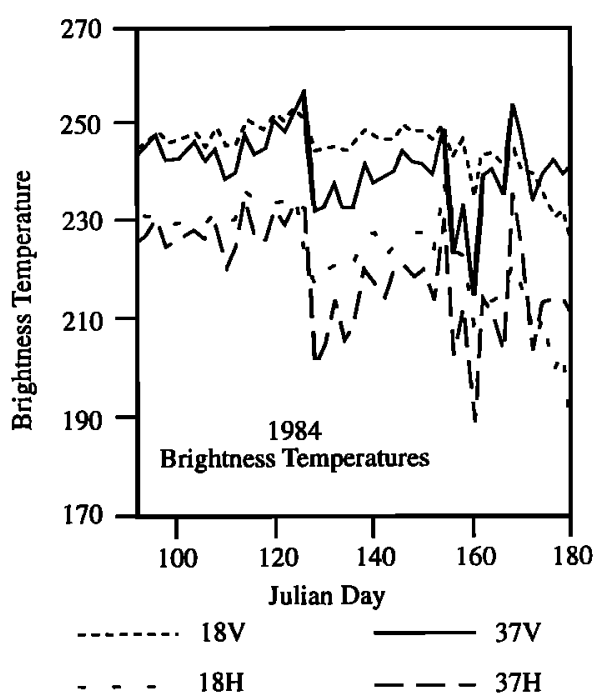

Figure 1. The 18- and 37-GHz brightness temperatures averaged over a 160 by $160 \mathrm{~km}$ block of pixels in the central southern Kara Sea for 1982 (a) and 1984 (b). 

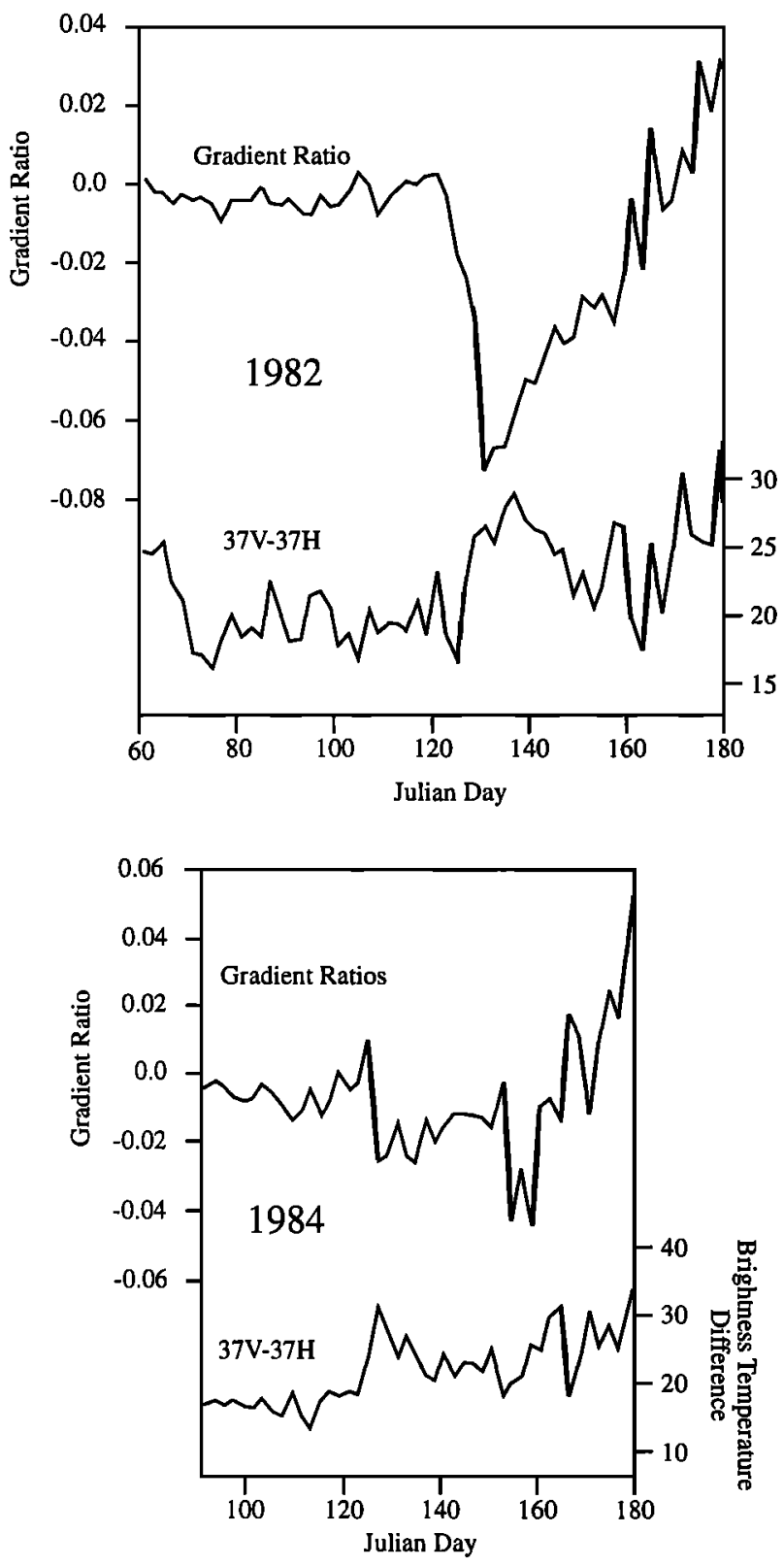

Figure 2. Gradient ratios and 37V-37H differences computed from the data in Figure 1 for 1982(a) and 1984 (b).

Using the gradient ratio isolates changes that are frequency dependent (such as changes in snow crystal size) from those that affect both frequencies together (such as a change in physical temperature). In the present case the drop in the 37$\mathrm{GHz}$ channel gives rise to negative gradient ratios. As negative gradient ratios are also indicative of multiyear ice, the present discussion of snow melt applies only to first-year ice regions. First-year ice in this context is defined in terms of microwave emissivity and represents ice that has not undergone a summer melt event. Once melt occurs, brine drainage from the ice pack changes the microwave emissivity significantly, and the resulting ice is referred to as multiyear ice regardless of its age. In practical terms, therefore, this analysis is limited to the seasonal sea ice zone in areas where there is little influx of multiyear ice from the Arctic Basin.

\section{Springtime brightness temperature changes in the Kara Sea: 1982 and 1984}

For this analysis the $18-\mathrm{GHz}$ and $37-\mathrm{GHz}$ brightness temperatures and the vertically polarized gradient ratios are averaged for an $180 \mathrm{~km}$ by $180 \mathrm{~km}$ block of pixels in the central portion of the southern Kara Sea. The brightness temperatures are plotted as a time series in Figure 1, and the gradient ratios are shown in Figure 2. The microwave data indicate that the southern Kara Sea remained ice covered through July in 1982 but that ice cover began to decrease in late June in 1984 and the region was clear of ice by July 7 of that year. The features of interest here are the episodic drops in brightness temperature that occur in both years.

These periods of lower brightness temperature are matched by periods of lower negative gradient ratios. Although brightness temperatures decrease at both $18 \mathrm{GHz}$ and $37 \mathrm{GHz}$, the drop at $37 \mathrm{GHz}$ is much greater. It is this increased difference that gives the increase in negative gradient ratios that would normally be interpreted as an increase in the multiyear ice fraction. After several weeks, however, the negative gradient ratios revert to the positive ratios characteristic of first-year ice. This drop in gradient ratios occurs too early in the season to be due to the formation of multiyear ice, and furthermore, multiyear ice once formed does not revert to first-year ice as this appears to do. An examination of the total and multiyear ice concentration maps for these time periods also shows that there is no advection of multiyear ice into or out of the area (possible sources of multiyear ice would be ice advected into the Kara Sea from the northeast or fast ice that remained along the coast from the previous summer). We will show later that in 1982 these changes occur under periods of extended clearsky conditions and are thus unlikely to be the result of an atmospheric effect. This indicates that the change in gradient ratios is due to a change in the emissivity of the first-year ice, and the most likely possibility is that it represents a change in the overlying snow cover. The timing of these emissivity changes is examined further in the present paper, using a radiative transfer model to calculate the surface radiative fluxes during this early spring period.

\section{The surface radiation budget}

The radiative transfer model is the same as that described by Francis et al. [1991] and uses a $\delta 2$-stream approach for calculating both solar and terrestrial fluxes. The $\delta 2$-stream solution is calculated for each layer in the model (where the column has been divided into layers having constant absorbing and scattering properties). The calculations are performed over 26 spectral intervals for the solar component $(0.25 \mu \mathrm{m}$ $4.3 \mu \mathrm{m})$ and for 18 intervals through the infrared spectrum from $4.5 \mu \mathrm{m}$ to $62.5 \mu \mathrm{m}$. Clouds are treated explicitly as scatterers in the visible, and as absorbing features in the infrared. The clouds are assumed to be perfect absorbers outside of the $8.3-\mu \mathrm{m}$ to $12.5-\mu \mathrm{m}$ window and to act as gray bodies within the window region, where the emissivity is calculated as a function of cloud liquid-water content. The liquid-water content, in turn, is estimated from the visible optical depth. Infrared absorption due to ozone, carbon dioxide, and water vapor is included, and random overlap is assumed between the water vapor continuum and other absorbing species. Absorption in the visible is by oxygen, ozone, and water vapor, and random overlap is again assumed for absorption by multiple species in 
the same spectral interval [Francis et al., 1991; Valero et al., 1989].

For the present application we assume isotropic reflectance at the surface and a solar albedo of $70 \%$. The surface infrared emissivity is taken to be 0.98 , and the calculations are performed once a day for the sun at local zenith (thus the calculations represent daily maximum values rather than daily averages). The model also requires vertical temperature and mixing ratio profiles, and these are obtained from stations surrounding the southern Kara Sea (on Novaya Zemlya to the west, Ostrov Vaygach to the south, and Ostrov Belyy to the east). These stations are located at approximately equal distances from the pixels used for the microwave samples, and the twice-daily radiosonde data are averaged for all three stations to produce the vertical profiles for the model. The cloud cover is estimated from the relative humidity profiles and compared with visible satellite imagery for 1984 . The visible imagery are from the Defense Meteorological Satellite Program (DMSP) operational linescan system at $2.7-\mathrm{km}$ resolution (similar imagery is not available for 1982). One hundred percent cloud cover is assumed to occur in any layer of the model that has $85 \%$ or greater relative humidity. Clouds are also included in the near-surface layers when the relative humidity is greater than $75 \%$ and is at least $40 \%$ greater than in the adjacent layers. Using these criteria, the presence or absence of clouds matches those observed in the visible imagery on about $93 \%$ of the days in 1984 . Of the 3 of 45 days that do not match, all three images show low cloud over the ice that is not apparent in the soundings at the surrounding stations. The cloud physical properties used in the model are based on the observations of Herman and Curry [1984] for summer Arctic stratus clouds, using an effective drop size radius of $7.5 \mu \mathrm{m}$.

The surface fluxes computed from the radiative transfer model are shown in Figures 3 and 4. The seasonal trend is

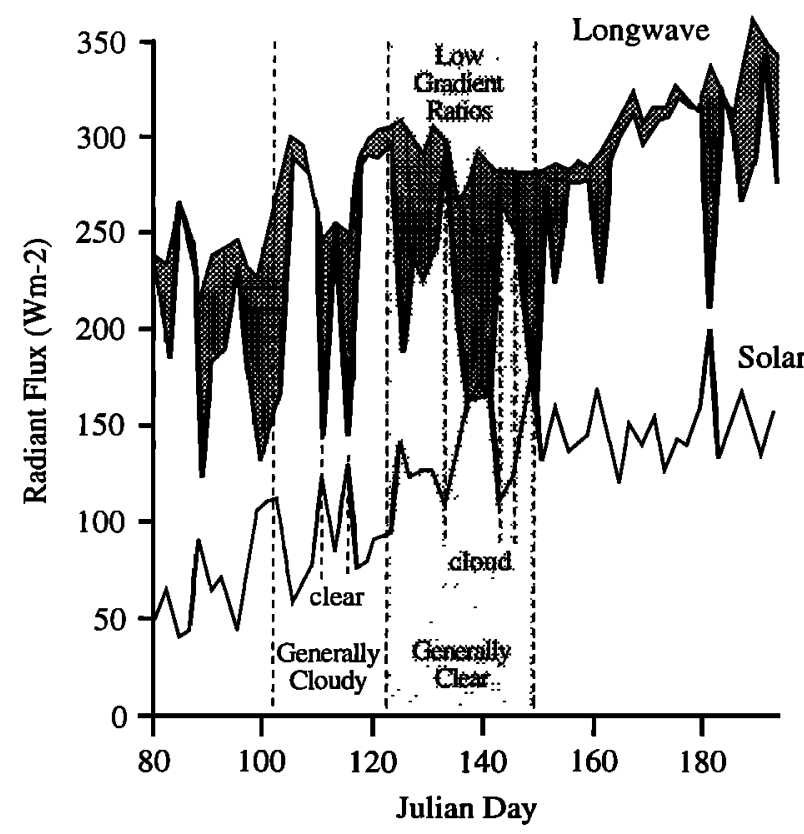

Figure 3. Radiation model results for 1982. The shaded regions correspond to the time period of strong negative gradient ratios. The upward longwave radiation is shown by the upper curve, and the shaded area gives the net longwave flux, which is usually negative (away from the surface).

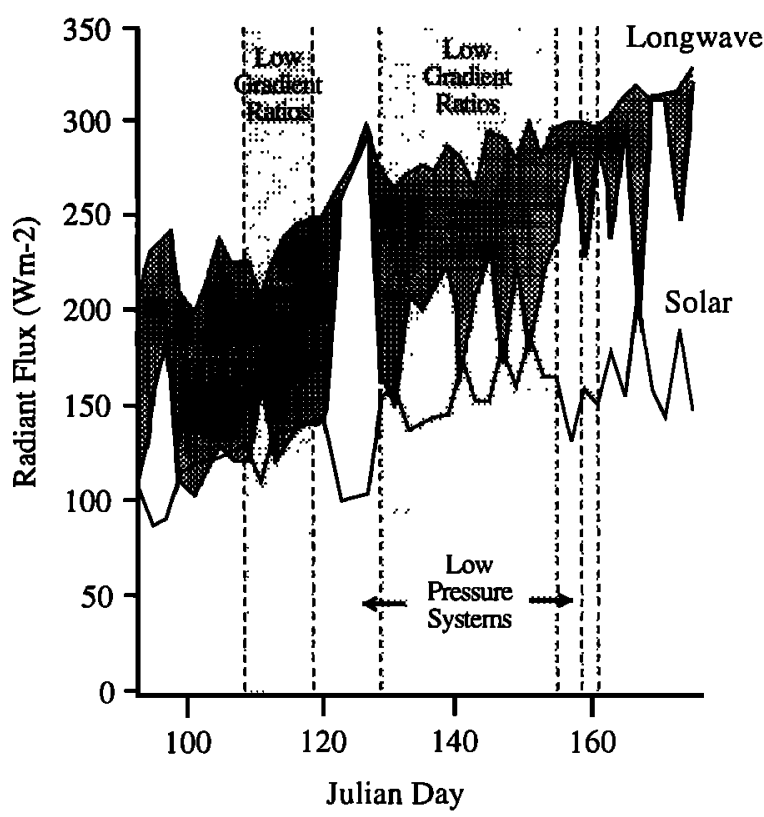

Figure 4. Radiation model results for 1984 . The shaded regions correspond to the time periods of strong negative gradient ratios. The upward longwave radiation is shown by the upper curve, and the shaded area gives the net longwave flux, which is usually negative (away from the surface).

obvious in both years, with the absorbed solar radiation increasing throughout the spring and then leveling off during the summer months. The large daily to weekly variations are due to changes in cloud cover, and the nature of the cloud cover is reflected in the flux calculations. For example, the radiosonde profiles indicate that most of the 1982 cloud cover is low-level stratus; cloud temperatures are similar to surface temperatures, and the outgoing and incoming longwave fluxes at the surface are virtually equal. On clear-sky days when the absorbed solar radiation increases, the upward longwave flux shows little change, and there is a large decrease in the downward longwave flux at the surface. In 1984, on the other hand, there is an increased incidence of cyclonic systems and a greater frequency of thicker or multilayered clouds, and the cloud layer is generally cooler than the surface.

\section{The premelt ice signature}

Looking first at 1984 (Figure 2b), one observes a large drop in gradient ratios on day 128 (May 7) and a further drop from day 156 to 160 (June 4-8). The DMSP satellite imagery indicates cloud cover associated with low-pressure systems moving through the region at these times. The brightness temperatures (Figure 1b) reach a peak just prior to the first drop in gradient ratios, coinciding with the arrival of the lowpressure system and the advection of warm air over the region. The radiosonde data show that surface temperatures reach the melting point, and the combination of high temperatures and low-level cloud results in peak values of the longwave fluxes (Figure 4), with the upward and downward fluxes being approximately equal. The drop in brightness temperatures on day 128 coincides with a retum to colder conditions as the low-pressure system moves out of the area. The negative gradient ratios are thus most likely to result from surface 
grain size and surface roughness changes due to surface melt and freeze cycles over the preceding 4 days.

Synoptic conditions during the second drop in gradient ratios in early June follow essentially the same pattern. In this case, however, the drop in gradient ratios is followed by a rapid increase in positive ratios (indicative of open water) as ice breakup advances. Although it is not obvious, there is some indication of a slight drop in gradient ratios earlier in the spring, well before any surface melt occurs. A similar but much larger decrease in gradient ratios is found in spring 1982 , and this requires a somewhat different interpretation.

Figure 2a shows that the large drop in the 1982 gradient ratios occurs after day 124 (May 4), and reaches a minimum on day 130 (May 10). The surface radiation budget indicates that the region was cloud covered from day 102 to day 122 (apart from two clear-sky days in the middle of the period). The net longwave flux during the premelt period was close to zero (Figure 3) except on the two clear days that had negative longwave budgets (upward IR $>$ downward IR). The absorbed solar radiation was also generally low, with values of about $60-80 \mathrm{~W} \mathrm{~m}^{-2}$. After day 122 and coincident with the drop in gradient ratios (Figure $2 \mathrm{a}$ ), a reversal occurs. There is a period of generally clear skies with a few isolated days of cloud cover. The longwave budget is strongly negative, and analysis of the station data shows that the surface air temperatures are below freezing. It is reasonable to expect, therefore, that the surface temperature over the ice is also below freezing at this point. The absorbed solar radiation, however, doubles, with values ranging from 125 to $170 \mathrm{~W} \mathrm{~m}^{-2}$ (except for the cloudy days when values drop to about $105-110 \mathrm{~W} \mathrm{~m}^{-2}$ ). These radiation budget calculations are discussed in relation to snow crystal growth calculations of Colbeck [1989a] and to observational studies done over the Greenland ice cap (Alley et al., 1990]; taken together they suggest that the emissivity changes in this case are due to the formation of a near-surface depth hoar following solar radiation into the pack and warming of the upper layers of the snow cover.

The role of solar penetration in the formation of depth hoar is discussed by Colbeck [1989a], who calculates rates of snow crystal growth under various surface temperature conditions with a snow model that includes the effects of solar penetration. For both a seasonal snow cover and an alpine snowpack, he calculates that diurnal radiative and temperature forcing cause rapid crystal growth in the near-surface layer. The snow-covered sea ice in the Kara Sea is analogous to Colbeck's seasonal snowpack case, where the temperature at the soil/snow interface is held at $0^{\circ} \mathrm{C}$, and crystal growth was calculated within a 1-m snowpack. In the present case, the radiation model shows that under clear-sky conditions the incoming solar radiation in the Kara Sea was within the ranges used by Colbeck for his model calculations. Colbeck, however, uses a $30^{\circ} \mathrm{C}$ diurnal temperature cycle, which is somewhat larger than would be likely over the sea ice. Colbeck also includes one polar example, for which he simulates conditions over a polar ice sheet. In this case, however, he assumes that a low value for radiative heating and depth hoar formation is linked to the annual temperature wave. The model shows penetrating radiation doubling the snow crystal growth rate at 20-cm depth over what would result from temperature cycling alone, but most of the crystal growth in the ice sheet model occurs in late summer and early fall. However, it has been shown that rapid depth hoar formation can also occur over polar ice much earlier in the summer [Alley et al., 1990].
Measurements taken on Greenland in the summer of 1990 show a 5- to 10-mm-thick depth hoar forming under clear-sky conditions in less than 24 hours [Alley et al., 1990]. This occurred at a depth of about a centimeter, where the solar loading caused a local temperature rise of several degrees compared to the temperature of the adjacent snow and air layers. The depth hoar formed in mid-June with maximum air temperatures well below freezing $\left(-8^{\circ} \mathrm{C}\right)$. The observed temperature gradient was sufficient to cause a net vapor movement out of the depth hoar, the diffusive mass flux alone accounting for the removal of an estimated $100 \mathrm{~kg} / \mathrm{m}^{3}$ from the depth hoar layer over a 3- to 5-day period. Given also the possibility of wind pumping [Clarke et al., 1987; Colbeck, 1989b] and thermal convection [Johnson et al., 1987], Alley et al. [1990] conclude that the energy available was sufficient to explain the observed density loss in terms of solar warming of the near-surface layer.

The reasons for the springtime emissivity changes in the Kara Sea cannot be proven unambiguously without in situ observations; the brightness temperature changes and the radiation model results, however, are consistent with the suggestion that the emissivity changes may be due to the formation of a near-surface depth hoar as a result of solar heating of the snowpack. The radiation budget calculations show that the surface longwave budget is negative, as is the sensible heat flux implied by the temperature profile. The only energy input to the surface is the incoming solar radiation, with the levels of penetrating radiation being within the ranges used by $\mathrm{Col}$ beck [1989a] to demonstrate hoar formation in a seasonal snowpack. The penetrating radiation heats the near-surface layer and amplifies the diumal temperature gradient, and the resulting mass flux causes a growth in snow crystal size. This increases the microwave scatter and reduces emissivity, with the change being frequency dependent (i.e. the scatter is a function of frequency in relation to crystal size; see, for example, Chang et al., [1976, 1982]). The increased scatter at 37 $\mathrm{GHz}$ results in a more negative gradient ratio.

Scattering in the snowpack is also polarization dependent and tends to be greater for horizontal polarizations [e.g., Mätzler, 1987]. Calculations of $37 \mathrm{~V}-37 \mathrm{H}$ are also presented in Figure 2. These show that the drop in gradient ratios is matched by an increase in the $37 \mathrm{~V}-37 \mathrm{H}$ difference, which further supports the suggestion that these brightness temperature changes result from a scattering effect. Why these regions of negative gradient ratios in the SSIZ should expand and then disappear is not clear. One possibility is that the near-surface layers, where the depth hoar occurs, may be further disturbed by wind action that would break down the layer and reduce the $37-\mathrm{GHz}$ and $18-\mathrm{GHz}$ brightness temperature differences.

\section{Conclusions}

SMMR-derived measurements over the first-year-ice region of the southern Kara Sea in spring 1982 and 1984 reveal areas of negative brightness temperature ratios that appear suddenly, persist for a couple of weeks, and then disappear. The gradient ratios in this case are calculated as the difference between the $37-\mathrm{GHz}$ and $18-\mathrm{GHz}$ vertically polarized brightness temperatures, and the negative ratios occur because of a sudden drop in brightness temperature at $37 \mathrm{GHz}$. These signatures are similar to occurrences reported during the early spring in other years and in other regions of the seasonal sea 
ice zone [Anderson, 1987]. Previous studies have shown that these regions are the first to exhibit snow and ice melt later in the spring, and these signatures are interpreted as representing the initial transition from winter to summer ice conditions.

The negative gradient ratios in 1982 occur in association with clear skies and below-freezing temperatures. Calculations of the surface radiation budget for these time periods show that the longwave flux is negative and that the only energy input to the snow surface results from incoming solar radiation (the radiosonde data indicate that the sensible heat flux would also be negative). Our conclusion is that the negative ratios represent areas of depth hoar in the near-surface layers that form as a consequence of solar heating. The growth in crystal size increases the scatter and reduces emission in the $37-\mathrm{GHz}$ channel, giving rise to the negative gradient ratios. For 1984 the radiation budget calculations show the possibility of surface melt and the formation of increased grain sizes and increased surface roughness following several days of freeze-thaw cycling. Why these signatures then disappear is unclear, but their disappearance may be due to further surface disturbance by wind action or precipitation.

Although the processes that give rise to the snow emissivity changes appear to be different in the two years, the significant fact is that in both years the microwave signal is regional and occurs as a response to changes in atmospheric temperature, cloud cover, and surface radiation budget. It is well known that ice retrievals are complicated in the summer by the emissivity change that accompanies the increase in liquid water in the pack. However, these results indicate that emissivity changes, which may introduce some error into the ice cover calculations, are also occurring much earlier in the spring and that the spatial and temporal distributions of these changes will be highly variable as a response to the synopticscale atmospheric circulation.

Acknowledgments. This work was supported by NASA grants NAGW-1042 to Robert Crane at The Pennsylvania State University and NAGW-1266 to Mark Anderson at the University of Nebraska. The SMMR gridded brightness temperature data on CD-ROM produced by $\mathrm{P}$. Gloersen were obtained from the National Snow and Ice Data Center, Boulder, Colorado. We would like to acknowledge the helpful comments made on an earlier draft of the paper by the editor and two anonymous referees.

\section{References}

Alley, R. B., E. S. Saltzman, K. M. Cuffey, and J. J. Fitzpatrick, Summertime formation of depth hoar in central Greenland, Geophys. Res. Lett. 17, 2393-2396, 1990.

Anderson, M. R., The onset of spring melt in first-year ice regions of the Arctic as determined from scanning multichannel microwave radiometer data for 1979 and 1980 , J. Geophys. Res., 92(C12), 13,153-13,163, 1987.

Anderson, M. R., and D. A. Robinson, Snow melt on Arctic sea ice in 1979 and 1980 from microwave and shortwave satellite data, Eos Trans. AGU, 66(46), 824, 1985.

Barry, R. G., Arctic Ocean ice and climate: Perspective on a century of polar research, Ann. Assoc. Am. Geogr., 73, 485$501,1983$.

Cavalieri, D. J., P. Gloersen, and W. J. Campbell, Determination of sea ice parameters with the Nimbus 7 SMMR, J. Geophys. Res., 89(D4), 5355-5369, 1984.
Chang, A. T. C., J. L. Foster, D. K. Hall, A. Rango, and B. K. Hartline, Snow water equivalent estimation by microwave radiometry, Cold Reg. Sci. Technol., 5, 259-267, 1982.

Chang, T. C., P. Gloersen, T. Schmugge, T. T. Wilheit, and H. J. Zwally, Microwave emission from snow and glacier ice, $J$. Glaciol., 16, 23-39, 1976.

Clarke, G. K. C., D. A. Fisher, and E. D. Waddington, Wind pumping: A potentially significant heat source in ice sheets, Publ. 170, pp. 169-180, Int. Assoc. for Hydrol. Sci., Gentbrugge, Belgium, 1987.

Colbeck, S. C., Snow crystal growth with varying surface temperatures and radiation penetration, J. Glaciol., 35, 23-39, 1989a.

Colbeck, S. C., Air movement in snow due to windpumping, $J$. Glaciol., 35, 209-213, 1989 b.

Crane, R. G., and M. R. Anderson, Spring melt patterns in the Kara/Barents Sea: 1984, GeoJournal, 18, 25-33, 1989.

Crane, R. G., R. G. Barry, and H. J. Zwally, Analysis of atmosphere-sea ice interactions in the Arctic Basin using ESMR microwave data, Int. J. Remote Sens., 3, 259-276, 1982.

Dickinson, R. E., G. A. Meehl, and W. M. Washington, Icealbedo feedback in a $\mathrm{CO}^{2}$-doubling simulation, Clim. Change, 10, 241-248, 1987.

Francis, J. A., T. P. Ackerman, K. B. Katsaros, R. J. Lind, and, K. L. Davidson, A comparison of radiation budgets in the Fram Strait summer marginal ice zone, J. Clim., 4, 218-235, 1991.

Gloersen, P., and D. J. Cavalieri, Reduction of weather effects in the calculation of sea ice concentration from microwave radiances, J. Geophys. Res., 9l(C3), 3913-3919, 1986.

Hanson, A., The snow cover of sea ice during the Arctic Ice Dynamics Joint Experiment 1975-1976, Arct. Alp. Res., 12, 215-226, 1980.

Herman, G. F. and J. A. Curry, Observational and theoretical studies of solar radiation in Arctic stratus clouds, J. Clim. Appl. Meteorol., 23, 5-24, 1984.

Johnson, J. B., M. Sturm, D. K. Perovich, and C. S. Benson, Field observations of thermal convection in a subarctic snow cover, Publ. 162, pp. 105-118, Int. Assoc. for Hydrol. Sci., Gentbrugge, Belgium, 1987.

Ledley, T. S., Snow on sea ice: Competing effect in shaping climate, J. Geophys. Res., 96(D9), 17,195-17,208, 1991.

Livingstone, C. E., K. P. Singh, and A. L. Gray, Seasonal and regional variations of active/passive microwave signatures of sea ice, IEEE Trans. Geosci. Remote Sens., GE-25, 159-173, 1987.

Mätzler, C., Application of the interaction of microwaves with the natural snowcover. Remote Sens. Rev., 2, 259-387, 1987.

Robinson, D. A., G. Scharfen, M. C. Serreze, G. Kukla, and R. G. Barry, Snow melt and surface albedo in the Arctic Basin, Geophys. Res. Lett., 13(9), 945-948, 1986.

Robinson, D. A., M. C. Serreze, R. G. Barry, G. Scharfen, and G. Kukla, Large-scale patterns and variability of snow melt and parameterized surface albedo in the Arctic Basin, J. Clim., 5, 1109-1119, 1992.

Shine, K. P., and R. G. Crane, The sensitivity of a onedimensional thermodynamic sea ice model to changes in cloudiness, J. Geophys. Res., 89(C6), 10,615-10,622, 1984.

Shine, K. P., and A. Henderson-Sellers, The sensitivity of a thermodynamic ice model to changes in surface albedo parameterization, J. Geophys. Res., 90(D1), 2243-2250, 1985.

Stiles, W. H. and F. T. Ulaby, The active and passive response to snow parameters, 1, Wetness, J. Geophys. Res., 85(C2), 10371044, 1980.

Valero, F. P. J., T. P. Ackerman, and W. J. Y. Gore, The effects of the Arctic haze as determined from airborne radiometer measurements during AGASP II, J. Atmos. Chem., 9, 225$244,1989$. 
Zwally, H. J., and P. Gloersen, Passive microwave images of the polar regions and research applications, Polar Rec., 18, 431450, 1977.

M. R. Anderson, Department of Geography, University of Nebraska, Lincoln, NE 68588-0135. (e-mail: manderson@crcvms.unl.edu)
R. G. Crane, College of Earth and Mineral Sciences, 103 Deike Building, The Pennsylvania State University, University Park, PA 16802-2710. (e-mail: crane@essc.psu.edu)

(Received September 25, 1992; revised September 1, 1993; accepted February 7, 1994.) 